\title{
Direct Transmission of Severe Fever with Thrombocytopenia Syndrome Virus from Domestic Cat to Veterinary Personnel
}

Atsushi Yamanaka, Yumi Kirino, Sho Fujimoto, Naoyasu Ueda, Daisuke Himeji, Miho Miura, Putu E. Sudaryatma, Yukiko Sato, Hidenori Tanaka, Hirohisa Mekata, Tamaki Okabayashi

Two veterinary personnel in Japan were infected with severe fever with thrombocytopenia syndrome virus (SFTSV) while handling a sick cat. Whole-genome sequences of SFTSV isolated from the personnel and the cat were $100 \%$ identical. These results identified a nosocomial outbreak of SFTSV infection in an animal hospital without a tick as a vector.

Severe fever with thrombocytopenia syndrome (SFTS) is caused by the species Dabie bandavirus (family Phenuiviridae, genus Bandavirus), generally called severe fever with thrombocytopenia syndrome virus (SFTSV) $(1,2)$. Cases of SFTS were identified in patients in China during 2009 (3) and subsequently in Japan and South Korea $(2,4)$. Clinical signs include high fever, fatigue, gastrointestinal symptoms, neurologic symptoms, thrombocytopenia, leukocytopenia, and multiorgan failure (5). SFTS is potentially fatal, and mortality rates have reached $27 \%$ in Japan (6). Although the clinical information regarding SFTS in most animals is unclear, cats show fatal symptoms similar to those in humans (7). Enzootic SFTSV transmission is primarily tickborne; tick bites can also spread the virus to humans (8) and animals (9). Human-to-human transmission occurs rarely through contact with infected blood, body fluids, or mucus (10) and possibly by aerosols (11). In this study, we provide evidence for the direct cat-to-human transmission of the virus, leading to a nosocomial outbreak of SFTSV infection.

Author affiliations: Miyazaki Prefectural Miyazaki Hospital, Miyazaki, Japan (A. Yamanaka, S. Fujimoto, N. Ueda, D. Himeji); University of Miyazaki, Miyazaki (Y. Kirino, P.E. Sudaryatma,

Y. Sato, H. Tanaka, H. Mekata, T. Okabayashi); Miyazaki

Prefectural Institute for Public Health and Environment, Miyazaki

(M. Miura)

DOI: https://doi.org/10.3201/eid2612.191513
The Study

Confirmatory testing of veterinary personnel samples was performed at the Laboratory of Microbiology, Miyazaki Prefecture Institute for the Public Health and Environment, Miyazaki, Japan. Cat sample analysis was performed at the Center for Animal Disease Control, University of Miyazaki. A 1-year-old male domestic cat was hospitalized on August 15, 2018, with jaundice, poor appetite, vomiting, and a rectal temperature of $40.4^{\circ} \mathrm{C}$. Hematologic examination showed leukocytopenia $(1,080$ cells $/ \mu \mathrm{L}$, reference range $4-30 \times 10^{3}$ cells $\left./ \mu \mathrm{L}\right)$, thrombocytopenia $(19,000$ cells $/ \mu \mathrm{L}$, reference range $9-90 \times 10^{4}$ cells $/ \mu \mathrm{L}$ ), and an increased level of total bilirubin $(3.1 \mathrm{mg} / \mathrm{dL}$, reference range $0-0.5 \mathrm{mg} / \mathrm{dL}$ ) (12) (Table). The cat died 3 days after hospitalization.

Serum samples, saliva samples, and anal swab specimens (sampled on the first day of hospitalization) were sent to the Center for Animal Disease Control, University of Miyazaki, for molecular test targeting the small segment RNA of SFTSV by reverse transcription PCR (RT-PCR) and real-time RT-PCR (3). The amounts of SFTSV RNA were quantified as RNA copies per milliliter of serum. We detected a viral load of $1.5 \times 10^{11}$ copies $/ \mathrm{mL}$ (Table).

During hospitalization, the cat came into contact with a veterinarian (44-year-old woman) and a veterinary technician (20-year-old woman). During contact, both veterinary personnel wore protective clothing (gloves and surgical masks), but their eyes remained unprotected; they were not bitten or scratched by the cat. In addition, neither was bitten by ticks.

After the death of the cat, symptoms consistent with SFTS developed in both veterinary personnel (Figure 1). Ten days after the death of the cat, on August 27, the veterinarian (patient 1) was hospitalized with a high fever (body temperature $39.2^{\circ} \mathrm{C}$ ), 
Table. Hematologic and diagnostic results from a nosocomial outbreak of infection with severe fever with thrombocytopenia syndrome virus in animal hospital, Japan, 2018*

\begin{tabular}{|c|c|c|c|c|c|c|c|c|c|}
\hline \multirow[b]{2}{*}{ Characteristic } & \multirow[b]{2}{*}{ Cat, $\uparrow$ Aug 15} & \multicolumn{6}{|c|}{ Patient 1} & \multicolumn{2}{|c|}{ Patient 2} \\
\hline & & Aug 27 & Aug 28 & Aug 29 & Aug 30 & Sep 5 & Sep 11 & Aug 28 & Sep 11 \\
\hline 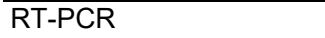 & + & - & - & + & + & ND & ND & + & ND \\
\hline Virus-specific lgG & + & - & - & ND & - & ND & + & - & + \\
\hline $\begin{array}{l}\text { Real-time RT-PCR, } \\
\text { copies/mL }\end{array}$ & $1.5 \times 10^{11}$ & ND & ND & $3.9 \times 10^{6}$ & $6.0 \times 10^{6}$ & ND & ND & $5.7 \times 10^{6}$ & ND \\
\hline Isolation $\ddagger$ & J1 & ND & ND & J1 & J1 & ND & ND & J1 & ND \\
\hline Leukocytes/ $\mu \mathrm{L}$ & $1,080\left(4-30 \times 10^{3}\right)$ & 1,970 & 1,300 & 1,060 & 1,450 & 2,570 & 4,070 & 2,850 & 4,630 \\
\hline Hemoglobin, g/dL & $14.6(9-18)$ & 13.1 & 12.6 & 12.3 & 13.4 & 11.6 & 12.6 & 13.4 & 13.1 \\
\hline Platelet count $/ \mu \mathrm{L}$ & $19,000\left(9-90 \times 10^{4}\right)$ & 81,000 & 63,000 & 53,000 & 59,000 & 155,000 & 214,000 & 254,000 & 261,000 \\
\hline Total bilirubin, $\mathrm{mg} / \mathrm{dL}$ & $3.1(0-0.5)$ & 0.36 & 0.26 & ND & 0.28 & 0.44 & 0.69 & 0.44 & 0.42 \\
\hline AST, IU/L & ND & 18 & 17 & 20 & 27 & 51 & 11 & 25 & 24 \\
\hline ALT, IU/L & $91(47.4-97.3)$ & 12 & 10 & 12 & 16 & 60 & 25 & 37 & 28 \\
\hline LDH, IU/L & ND & 134 & 123 & 149 & 157 & 130 & 156 & 213 & 267 \\
\hline C-reactive protein, $\mathrm{mg} / \mathrm{dL}$ & ND & 0.04 & 0.04 & ND & 0.03 & 0.01 & 0.002 & 0.17 & 0.19 \\
\hline
\end{tabular}

${ }^{*} \mathrm{ALT}$, alanine aminotransferase; AST, aspartate aminotransferase; J1, J1 genotype; LDH, lactate dehydrogenase; ND, not done; RT-PCR, reverse transcription PCR; -, negative; + , positive.

†Values in parentheses are standard feline hematologic parameters reported by O'Brien et al. (12).

$\ddagger$ Virus isolated on Vero cells and genotyping.

fatigue, widespread myalgia, ocular pain, and bicytopenia. No abnormal symptoms were noted on cardiac, pulmonary, or abdominal examination. Hematologic examinations showed leukocytopenia and thrombocytopenia. On postadmission days 2 and 3, the presence of SFTSV RNA was confirmed in the serum samples by RT-PCR and real-time PCR (day 2, $3.9 \times 10^{6}$ virus RNA copies/mL; day 3, $6.0 \times 10^{6}$ virus RNA copies/mL) (Table). By postadmission day 10 , the symptoms of SFTS abated, and patient 1 was discharged. Five days after discharge (September 11, 2018), SFTSV-specific IgG were detected in serum samples (13) (Table).
Eleven days after the death of the cat, on August 28 , the veterinary technician (patient 2) also had fever and general malaise but less severe leukocytopenia. Serum samples collected from patient 2 were positive for SFTSV RNA by RT-PCR, and SFTSV RNA copies were quantified by using real-time RT-PCR $\left(5.7 \times 10^{6}\right.$ virus RNA copies/mL) (Table). However, patient 2 recovered without being hospitalized. Similar to patient 1, IgG against SFTSV was present in serum collected from patient 2 on September 11.

We also isolated the virus. Vero cells were inoculated with SFTSV-positive serum samples taken from the cat, patient 1 , and patient 2 . The cells were adjusted

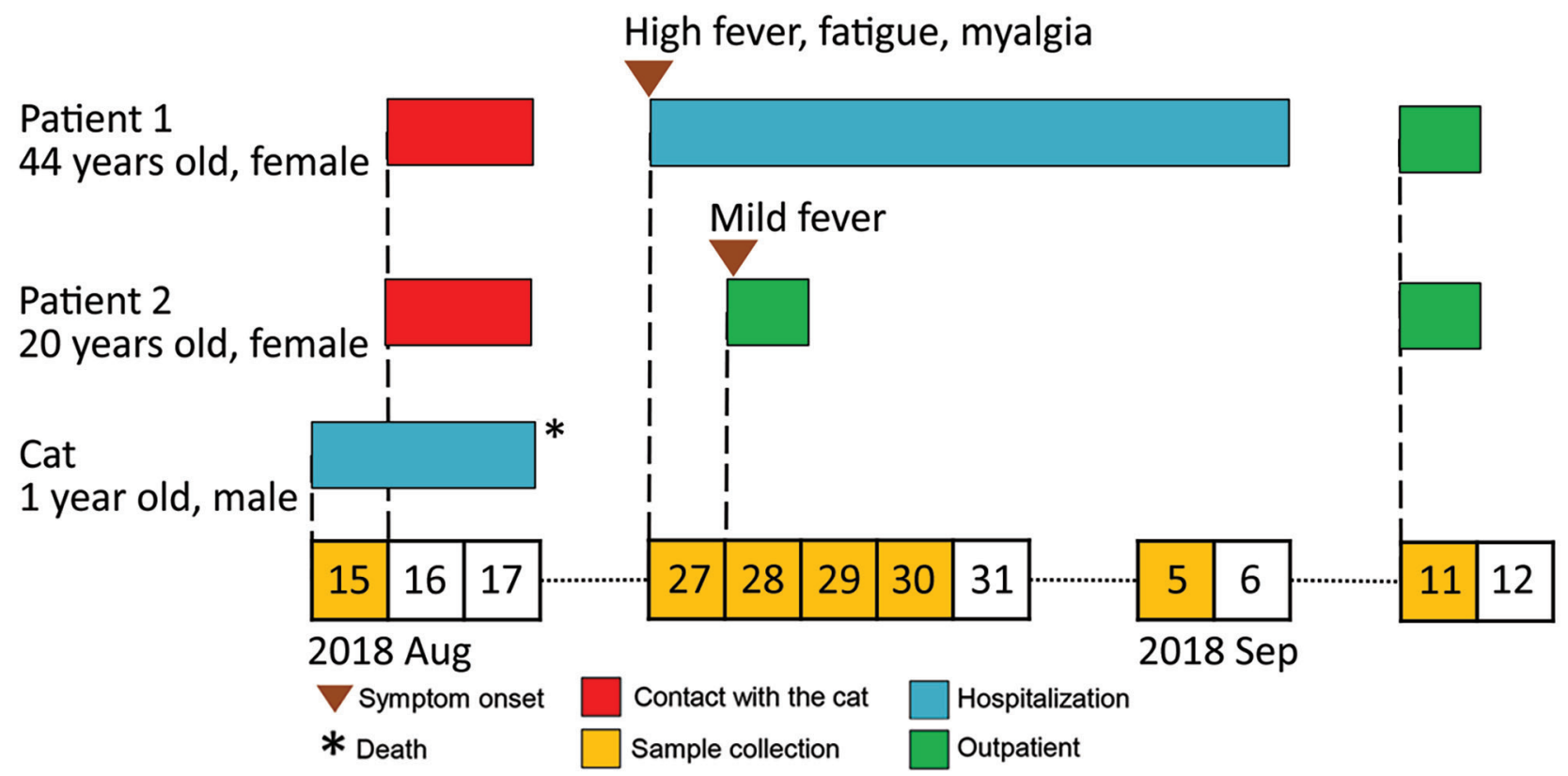

Figure 1. Timeline for transmission of severe fever with thrombocytopenia syndrome virus from cat to veterinary personnel in animal hospital, Japan, 2018. Patient 1, veterinarian; patient 2, veterinary technician. 


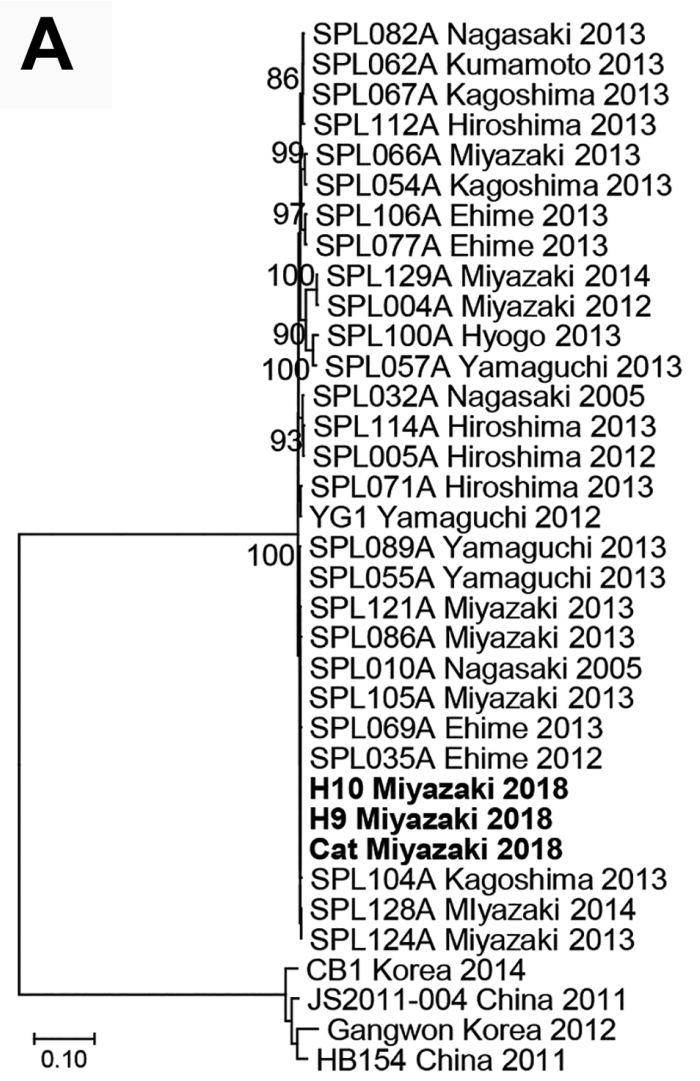

\section{C $\quad$ Cat Miyazaki 2018} H9 Miyazaki 2018
H10 Miyazaki 2018

100. SPL089A Yamaguchi 2013

SPL055A Yamaguchi 2013 SPL069A Ehime 2013

10 o' SPL035A Ehime 2012

SPL104A Kagoshima 2013

87, SPL128A Mlyazaki 2014

93 SPL124A Miyazaki 2013

99 SPL121A Miyazaki 2013

- SPL010A Nagasaki 2005

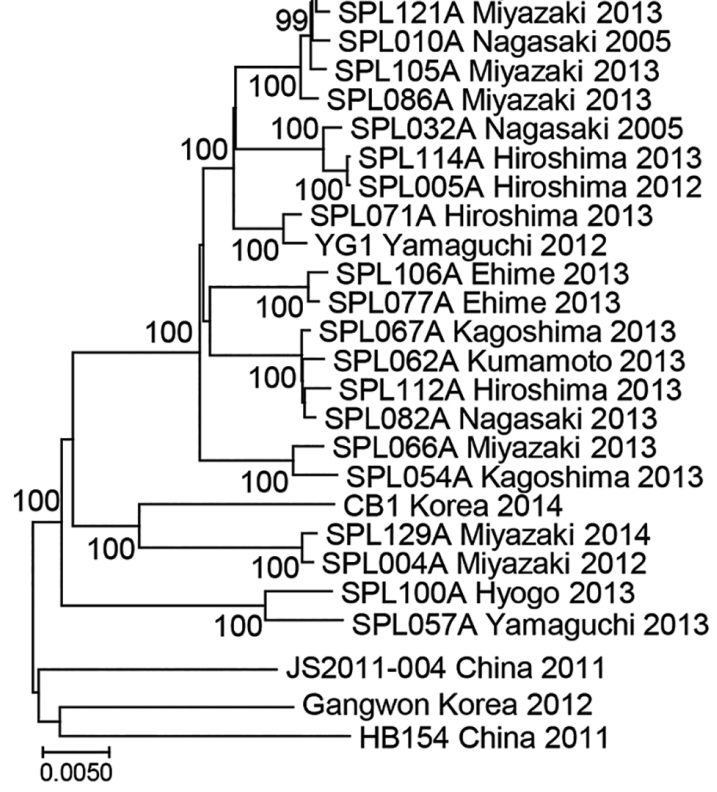

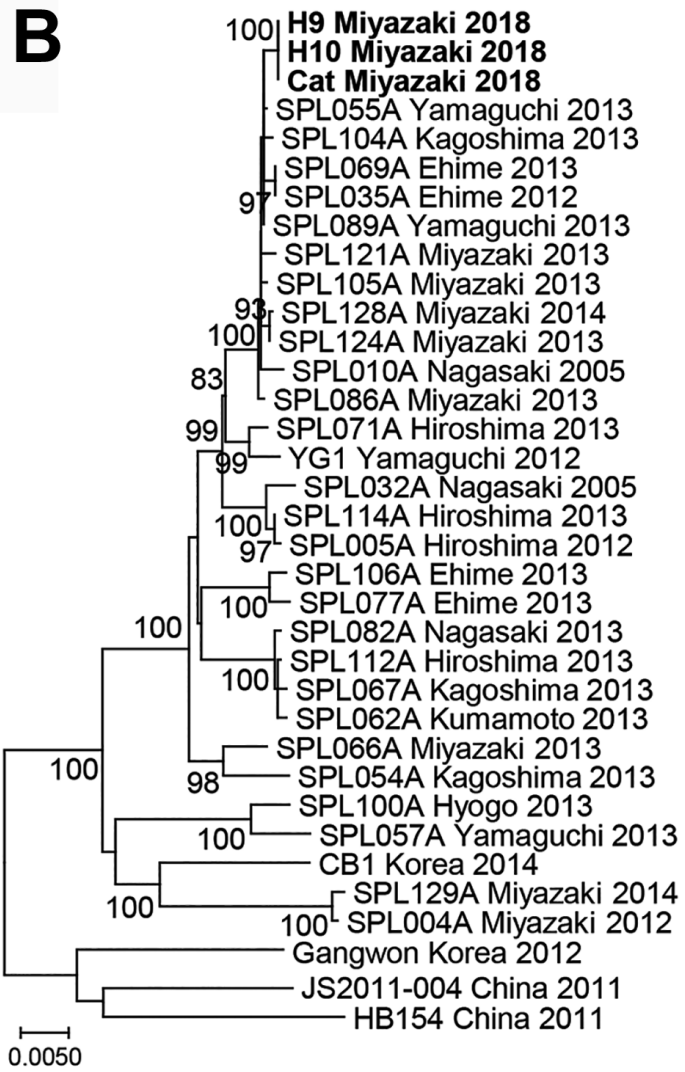

Figure 2. Phylogenetic analyses of severe fever with thrombocytopenia syndrome virus strains obtained from a cat and veterinary personnel in animal hospital, Japan, 2018. A) Small; B) medium; and C) large viral genomic RNA segments. Bold indicates H9/Miyazaki/2018 (from patient 1), H10/Miyazaki/2018 (from patient 2), and cat/Miyazaki/2018 (from cat). Scale bars indicate nucleotide substitutions per site. 
to $10^{5}$ cells $/ \mathrm{mL}$ and seeded onto a 12-well plate (Sumilon, http:/ / www.sumilon.com) overnight as a monolayer ( $>60 \%$ confluence). A total of $200 \mu \mathrm{L}$ of serum samples was inoculated into the cells. For all 3 serum samples (cat, patient 1 , and patient 2 ), extensive cytopathic effects were observed after 3 days of incubation, and a high copy number of SFTSV RNA was detected in the cell supernatants.

Whole-genome sequencing (MiSeq; Illumina, https://www.illumina.com) of the viruses (named Cat/Miyazaki/2018, H9/Miyazaki/2018, and H10/ Miyazaki/2018) was conducted as described (14), and sequences were submitted to DDBJ (accession nos. LC462229-37). For each viral RNA segment (small, medium, and large), the viral sequences from the cat and the 2 veterinary personnel showed 100\% homology (Figure 2) and were closely related to the reference SFTSV strain YG1 from Japan (YG1/Yamaguchi/2012, accession nos. AB817995, AB817997, and AB817999). Furthermore, the sequence of the small segment was closely related to the SFTSV strains SPL128A Miyazaki 2014 and SPL124A Miyazaki 2013 (Figure 2, panel A), which were obtained from SFTS patients in the same prefecture during 2013-2014. Sequences of the medium and large segments were more distantly related to the SPL128A Miyazaki 2014 and SPL124A Miyazaki 2013 viruses, suggesting that they might have evolved from these strains (Figure 2, panels B, C).

SFTS is an emerging epizootic infectious disease and is transmitted primarily by ticks. However, some cases of SFTS do not involve ticks, and human-to-human transmission by aerosols (10) or through contact with infected blood or other body fluids $(6,9)$ has been reported. Furthermore, a transmission route of SFTSV from a cat to a human has been confirmed with a partial nucleotide sequence of SFTSV in serum samples (15). In this report, we demonstrated a direct cat-to-human nosocomial outbreak of SFTSV with the following evidence: SFTSV was isolated from serum samples obtained from a cat and 2 veterinary personnel; the complete nucleotide sequence (segments small, medium, and large) of SFTSV from the cat and the 2 veterinary personnel showed $100 \%$ identity; the veterinary personnel were not bitten by ticks, nor were they bitten or scratched by the cat; and SFTS-like symptoms developed in the 2 veterinary personnel $\approx 10$ days after close contact with the cat.

\section{Conclusions}

Our results show that SFTSV can be transmitted to humans in the absence of ticks and that wearing limited protective clothing (e.g., face masks and rubber gloves) is insufficient to protect veterinary personnel from infection when handling infected animals. It is likely that cat-to-human transmission occurred by aerosols or contact with infected cat blood or other body fluids. This study draws attention to occupational exposure to potentially fatal zoonotic pathogens and highlights the need for stringent biosafety measures (i.e., personal protective clothing and equipment) to be in place when handling animals with symptoms of SFTS. These measures should include protection against aerosols that can be generated during treatment.

\section{Acknowledgments}

We thank the patients for providing permission to report their clinical symptoms and disease course.

This study was supported by the Special Education and Research Expenses, Ministry of Education, Culture, Sports, Science and Technology, Japan.

\section{About the Author}

Dr. Yamanaka is a chief physician in the Department of Internal Medicine, Miyazaki Prefectural Miyazaki Hospital, Miyazaki, Japan. His primary research interests are emerging infectious diseases and clinical microbiology.

\section{References}

1. International Committee on Taxonomy of Viruses. Virus taxonomy. 2019 release EC 51. Berlin, July 2019; Email ratification 2020 (MSL \#35) [cited $2020 \mathrm{Jul}$ 9]. https://talk.ictvonline.org/taxonomy/p/taxonomyhistory?taxnode_id=20141803

2. Takahashi T, Maeda K, Suzuki T, Ishido A, Shigeoka T, Tominaga $\mathrm{T}$, et al. The first identification and retrospective study of severe fever with thrombocytopenia syndrome in Japan. J Infect Dis. 2014;209:816-27. https:/ / doi.org/ 10.1093/infdis/jit603

3. Yu XJ, Liang MF, Zhang SY, Liu Y, Li JD, Sun YL, et al. Fever with thrombocytopenia associated with a novel bunyavirus in China. N Engl J Med. 2011;364:1523-32. https:/ / doi.org/10.1056/NEJMoa1010095

4. Kim KH, Yi J, Kim G, Choi SJ, Jun KI, Kim NH, et al. Severe fever with thrombocytopenia syndrome, South Korea, 2012. Emerg Infect Dis. 2013;19:1892-4. https://doi.org/10.3201/ eid1911.130792

5. Kato H, Yamagishi T, Shimada T, Matsui T, Shimojima M, Saijo M, et al.; SFTS epidemiological research group-Japan. Epidemiological and clinical features of severe fever with thrombocytopenia syndrome in Japan, 2013-2014. PLoS One. 2016;11:e0165207. https:// doi.org/10.1371/journal. pone. 0165207

6. Kobayashi $Y$, Kato H, Yamagishi T, Shimada T, Matsui T, Yoshikawa T, et al.; SFTS Epidemiological Research Group Japan. Severe fever with thrombocytopenia syndrome, Japan, 2013-2017. Emerg Infect Dis. 2020;26:692-9. https://doi.org/10.3201/eid2604.191011 
7. Matsuu A, Momoi Y, Nishiguchi A, Noguchi K, Yabuki M, Hamakubo E, et al. Natural severe fever with thrombocytopenia syndrome virus infection in domestic cats in Japan. Vet Microbiol. 2019;236:108346. https://doi.org/10.1016/j.vetmic.2019.06.019

8. Yun SM, Lee WG, Ryou J, Yang SC, Park SW, Roh JY, et al. Severe fever with thrombocytopenia syndrome virus in ticks collected from humans, South Korea, 2013. Emerg Infect Dis. 2014;20:1358-61. https://doi.org/10.3201/eid2008.131857

9. Oh SS, Chae JB, Kang JG, Kim HC, Chong ST, Shin JH, et al. Detection of severe fever with thrombocytopenia syndrome virus from wild animals and ixodidae ticks in the Republic of Korea. Vector Borne Zoonotic Dis. 2016;16:408-14. https://doi.org/10.1089/vbz.2015.1848

10. Liu Y, Li Q, Hu W, Wu J, Wang Y, Mei L, et al. Person-toperson transmission of severe fever with thrombocytopenia syndrome virus. Vector Borne Zoonotic Dis. 2012;12:156-60. https:/ / doi.org/10.1089/vbz.2011.0758

11. Gong Z, Gu S, Zhang Y, Sun J, Wu X, Ling F, et al. Probable aerosol transmission of severe fever with thrombocytopenia syndrome virus in southeastern China. Clin Microbiol Infect. 2015;21:1115-20. https:/ / doi.org/10.1016/j.cmi.2015.07.024

12. O'Brien M, Murphy MG, Lowe JA. Hematology and clinical chemistry parameters in the cat (Felis domesticus).
J Nutr. 1998;128(Suppl):2678S-9S. https:/ / doi.org/10.1093/ jn/128.12.2678S

13. Fukuma A, Fukushi S, Yoshikawa T, Tani H, Taniguchi S, Kurosu T, et al. Severe fever with thrombocytopenia syndrome virus antigen detection using monoclonal antibodies to the nucleocapsid protein. PLoS Negl Trop Dis. 2016;10:e004595. https://doi.org/10.1371/ journal.pntd.0004595

14. Mekata H, Yamamoto M, Hamabe S, Tanaka H, Omatsu T, Mizutani T, et al. Molecular epidemiological survey and phylogenetic analysis of bovine influenza $\mathrm{D}$ virus in Japan. Transbound Emerg Dis. 2018;65:e355-60. https:/ / doi.org/ 10.1111/tbed.12765

15. Kida K, Matsuoka Y, Shimoda T, Matsuoka H, Yamada H, Saito T, et al. A case of cat-to-human transmission of severe fever with thrombocytopenia syndrome virus. Jpn J Infect Dis. 2019;72:356-8. https:// doi.org/10.7883/ yoken.JJID.2018.526

Address for correspondence: Tamaki Okabayashi, Center for Animal Disease Control, University of Miyazaki, 1-1 Gakuenkibanadai Nishi, Miyazaki 889-2192, Japan; email: okbys81@cc.miyazaki-u.ac.jp

\section{January 2020 Viruses}

- Spatial Epidemiologic Trends and Hotspots of Leishmaniasis, Sri Lanka, 2001-2018

- Candidatus Mycoplasma haemohominis in Human, Japan

- Nutritional Care for Patients with Ebola Virus Disease

- Paid Leave and Access to Telework as Work Attendance Determinants during Acute Respiratory Illness, United States, 2017-2018

- Preclinical Detection of Prions in Blood of Nonhuman Primates Infected with Variant Creutzfeldt-Jakob Disease

- Effect of Acute Illness on Contact Patterns, Malawi, 2017

- Outbreak of Peste des Petits Ruminants among Critically Endangered Mongolian Saiga and Other Wild Ungulates, Mongolia, 2016-2017

- Elephant Endotheliotropic Herpesvirus Hemorrhagic Disease in Asian Elephant Calves in Logging Camps, Myanmar

- Risk Factors for and Seroprevalence of Tickborne Zoonotic Diseases among Livestock Owners, Kazakhstan

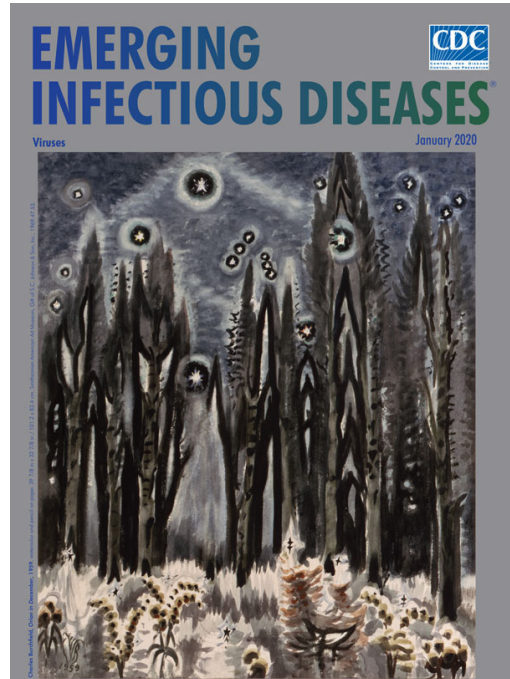

- High Azole Resistance in Aspergillus fumigatus Isolates from Strawberry Fields, China, 2018

- Tick-Borne Encephalitis Virus, United Kingdom

- Emergence of Vibrio cholerae 01 Sequence Type 75 in Taiwan
- High Pathogenicity of Nipah Virus from Pteropus lylei Fruit Bats, Cambodia

- Varicella in Adult Foreigners at a Referral Hospital, Central Tokyo, Japan, 2012-2016

- Geographic Distribution and Incidence of Melioidosis, Panama

- Shigella Bacteremia, Georgia, USA, 2002-2012

- Distribution of Japanese Encephalitis Virus, Japan and Southeast Asia, 2016-2018

- Novel Reassortant Highly Pathogenic Avian Influenza A(H5N2) Virus in Broiler Chickens, Egypt

- Infectivity of Norovirus GI and GII from Bottled Mineral Water during a Waterborne Outbreak, Spain

- Visceral Leishmaniasis, Northern Somalia, 2013-2019

- Influenza D Virus of New Phylogenetic Lineage, Japan

- Diagnosis of Syphilitic Bilateral Papillitis Mimicking Papilloedema

\section{EMERGING} INFECTIOUS DISEASES
To revisit the January 2020 issue, go to: https://wwwnc.cdc.gov/eid/articles/issue/26/1/table-of-contents 